\title{
Biofilm Adhesiveness is a Reliable Proxy for the Effect Assessment of Silver Nanoparticles on the Functionality of Freshwater Biofilms
}

\author{
Schmidt $\mathrm{H}^{1 *}$, Gerbersdorf $\mathrm{SU}^{2}$, Ullrich $\mathrm{X}^{2}$, Thom \\ $\mathrm{M}^{3}$ and Manz $\mathbf{W}^{1}$ \\ ${ }^{1}$ Institute for Intergrated Natural Siences, University \\ Koblenz-Landau, Germany \\ ${ }^{2}$ Insitute for Modelling hydraulic and Environmental \\ Systems, University of Stuttgart, Germany \\ ${ }^{3}$ Forschungszentrum Küste, Leibniz Universität \\ Hannover, Germany \\ *Corresponding author: Schmidt H, Department for \\ Integrated Natural Sciences University Koblenz-Landau, \\ Germany
}

Received: September 21, 2017; Accepted: January 23, 2018; Published: January 30, 2018

\begin{abstract}
A sediment mesocosm was used for the cultivation of complex lotic biofilms under controlled natural-like conditions. The matured biofilms were exposed to environmentally relevant concentrations of Silver Nanoparticles (AgNPs) characterized by a variety of state of the art technologies. The aim of this study was to address the ecotoxicological damage potential of this exposure for the benthic biofilm system and associated ecosystem functions. Microbial biomass (bacteria and algae) as well as colloidal EPS protein and carbohydrate contents were assessed for a period of 18 days after the treatment. None of these parameters displayed a significant development or differences between exposed and control biofilms. However, the assessment of biofilm adhesiveness using the Mag-PI system showed highly significant effects of the exposure and was a reliable proxy for the non-lethal impact of AgNPs on the biofilm functionality. This complex sum parameter constitutes a result of various in parts still unraveled interactions within the biofilm matrix. It is precisely for this reason why The Measurement of Biofilm Adhesiveness using MagPI has to be integrated in the ecotoxicological tool box as a direct in situ method for the assessment of effects on biofilm structure and stability to influence the functionality of the overall benthic ecosystem.
\end{abstract}

Keywords: Silver Nanoparticles (Agnps); Magpi, Measurement of Biofilm Adhesiveness; Biofilm Adhesiveness; Freshwater Biofilm; EPS; Sediment Mesocosm; Biostabilization; Fine Sediments

\section{Introduction}

Freshwater biofilms have great ecological relevance and are essential for aquatic habitats. The biofilm microbes not only constitute the base of the aquatic food web, the benthic pelagic feedback loop and the microbial loop make different nutrient available for other larger organisms such as makrophytes. Moreover, benthic biofilms play a significant role in the process of auto purification and can function as a trap for persistent contaminations and pollutants. Even more, during the process of biostabilization [1], benthic biofilms can significantly increase the stability of fine sediments and thus prevent a re-suspension of legacies [2-4].

Due to this variety of important ecosystem functions and an even greater number potential stressors which can impact these biofilm services, research into the reaction of benthic systems and biofilms after disturbance is increasingly expedited. As examples, the development of biofilms after an exposure to stressors such as desiccation $[5,6]$ or antibiotics $[7,8]$ was investigated. Furthermore, different survival strategies of biofilm microbes were studied in more detail such as morphological changes in bacteria due to stress [9] or different stages of dormancy in case of nutrient deficiency in bacteria that do not form spores [10]. There are also first insights into the resilience of the microbial community of a drinking water system and how stress can induce changes in the community composition [11]. However, reliable and measurable markers for the functionality of the biofilm system and its ecosystem services were hardly addressed. The investigation of Weaver et al. [12] assessing the resilience of the enzyme activity of ground water biofilms constitutes a suitable example of this required new comprehensive perspective as microbial enzyme activity can be essential for ground water quality and the total habitat. The adhesiveness of the biofilm constitutes another example of an essential ecosystem function: it significantly influences the development of the biofilm matrix and shapes the rate of attachment and detachment of particles and flocs [13], and thus the mass balance in the system of biofilm and fine sediment. Furthermore, the process of biostabilization is depending on biofilm stability and adhesiveness which is directly measurable using the MagPI-IP (Magnetic Particle Induction - Image Processing) [14].

First insights into the impact of different boundary conditions e.g. light intensity, flow velocity or seasonality upon microbial limnicbiostabilization could be gathered $[15,16]$. Furthermore, anthropogenic pollution was demonstrated to impact the ecosystem service biostabilization [2]. However, there is still a great lack of knowledge regarding the actual ecotoxicological potential of newly emerging substances. Engineered nanoparticles constitute an example for these substances emitted without profound knowledge about their fate in the environment. Generally, these industrial nanoparticles are used in the manufacturing process of a variety of different products such as textiles, cosmetics and pharmaceutics. The main reason for the addition of these nanoparticles e.g. containing titaniumdioxid, gold, 




Figure 1: Schematic draw of the experimental setup. Left: side view; right: top view on straight flume. a) reservoir tank; b) pump; c) inlet pipeline; d) straight flume; e) partition; f) outlet pipeline; g) sediment cartridge; h) fluorescent tube. Arrows indicate flow direction.

\begin{tabular}{|c|c|c|c|c|c|c|c|}
\hline \multirow[b]{2}{*}{09} & \multirow[b]{2}{*}{10} & \multirow[b]{2}{*}{11} & \multicolumn{2}{|c|}{ Flume 1} & \multirow[b]{2}{*}{14} & & \\
\hline & & & 12 & 13 & & 15 & 16 \\
\hline 08 & 07 & 06 & 05 & 04 & 03 & 02 & 01 \\
\hline & & & & & & & \\
\hline 25 & 26 & 27 & 28 & 29 & 30 & 31 & 32 \\
\hline 24 & 23 & 22 & 21 & 20 & 19 & 18 & 17 \\
\hline
\end{tabular}

\section{$\square$ minimal}

Figure 2: Results of the biofilm adhesiveness assessment prior to the different treatments.

copper or silver is their antimicrobial effect which should increase the shelf life and usability of the products which may result in a potential adverse effect upon limnic biofilms. Thus, research of the ecological effects of nanoparticles was focused in the DFG project "Internano" in order to assess the associated damage potential and resulting ecological thread. In this context, recent studies $[17,18]$. focused on Silver Nanoparticles (AgNPs) as they have a major fraction of all manufactured and used nanoparticles: it could be demonstrated that even an exposure to a sub-lethal concentration of AgNPs significantly impacted the structure and stability of model freshwater biofilms.

This study aimed to broaden the gathered knowledge about the effects of AgNPs upon the functionality of freshwater biofilms. In contrast to the aforementioned investigations, natural complex biofilms were analyzed in order to increase the ecological validity of the results. Furthermore, the short term as well as the long term development of the biofilms after an exposure to different concentrations of AgNPs was assessed. In doing so, a central question was how the adhesiveness of the biofilm isaffected by the exposure to AgNPs. There are two reasons why this parameter was assessed in an extensive measurement campaign to evaluate its suitability as an indicator for ecological stress: firstly, the reliability of biofilm adhesiveness as a marker for biofilm stability and biostabilization could be shown recently [15]. Secondly, its sensitivity to other adverse effects such as Triclosan [19], was previously demonstrated. Furthermore, if there is a measurable reaction in the microbial biostabilization capacity of the analyzed biofilms, the determination of biofilm adhesiveness could constitute new and essential straight forward tool for future risk assessment as well as monitoring and sediment management strategies.

\section{Material and Methods}

\section{Experimental setup}

Natural biofilms were cultivated in a setup consisting of two independent mesocosms (length $\mathrm{x}$ width $\mathrm{x}$ height: $0,70 \mathrm{x} 0,25 \mathrm{x} 0,16 \mathrm{~m}$ each; (Figure 1) with individual water reservoir and water circulation. 50Liters of fluvial water and suspended sediment gathered from the river Enz (Roßwag, Baden-Württemberg, Germany) were transferred into each flume/ reservoir tank. A pump (380 Bilge Pump 380 GPH, PENTAIR, Herentals, Belgium) with a flow rate of $1438 \mathrm{l} \mathrm{h}^{-1}$ ensured a constant water circulation through the flume of each mesocosm. Thus, the floating microbial community developed as biofilm on the provided substrate (inert glass beads, diameter 150-200 $\mu \mathrm{m}$ ) which was filled in 32 rectangular cartridges (length $\mathrm{x}$ width $\mathrm{x}$ height: $0.08 \mathrm{~m} \times 0.06 \mathrm{~m} \times 0.02 \mathrm{~m}$ ). The illumination was set using daylight fluorescence tubes (OsramBiolux; $480-665 \mathrm{~nm}$ ) in a day-night rhythm of 10/14 h illumination/darkness.

\section{Experimental Proceeding}

\section{Initial preparation}

Four sets of 8 cartridges each were formed with the aim of guaranteeing comparable initial biofilm adhesiveness of approximately 455 to $495 \mathrm{~mA}$ over all different sets (see section microbial biostabilization below). In order to achieve this aim, the adhesiveness of all biofilms was measured using MagPI (Figure 2) hereafter referred to day one of the experiment after aninitial cultivation period of six weeks (18.1. -29.2.2016) under stable boundary conditions. The determined biofilm adhesiveness was categorized in four different stability levels and two biofilms of each level were summarized to one set of 8 cartridges (Figure 3 ) with very similar mean biofilm adhesiveness.

\section{Treatment and Sampling}

Each of the 32 biofilm covered sediment cartridges was transferred to a separate container (length $\mathrm{x}$ width $\mathrm{x}$ height: $0,14 \times 0,10 \times 0,04$ $\mathrm{m}$ ) filled with river water, aired, and illuminated in the same way as the flumes (day/night: 10/ $14 \mathrm{~h}$ ). After $20 \mathrm{~h}$, biofilm adhesiveness was determined prior to the different treatments. The concentrations of AgNPs and AgNO3were chosen as previous experiments $[18,20]$ showed their impact on the structure and stability of mono species biofilms: one set of 8 cartridges was exposed to $600 \mu \mathrm{g}^{*} \mathrm{l}^{-1} \mathrm{AgNP}$ (T1), another set was treated with $2.4 \mathrm{mg}^{*} \mathrm{l}^{-1}$ (T2), and $2.4 \mathrm{mg}^{*} \mathrm{l}^{-1} \mathrm{AgNO}_{3}$ (T3) was added to the last set, while one set of 8 biofilms constituted the untreated control (C) - (Figure 3). Further information about the characteristics of the used silver nanoparticles can be found in Metreveli, Philippe \& Schaumann [21] and Metreveliet al. [22]. Sampling and determination of biofilm adhesiveness was performed $24 \mathrm{~h}$ after the treatments as well as 3, 5, 8 and 18 days after the treatment. After biofilm adhesiveness was measured, biofilm samples for the determination of microbial biomass and the EPS components were taken of the same biofilm spots to correlate the different parameters. A sterile disposable syringe with a cut-off head was used to stamp round samples of $0.01 \mathrm{~m}$ diameter and $0.005 \mathrm{~m}$ depth out of the biofilm resulting in a single biofilm/ sediment sample of 0.5 


\begin{tabular}{|c|c|c|c|c|c|c|c|c|}
\hline \begin{tabular}{|l|}
$\mathrm{C}$ \\
\end{tabular} & 04 & 22 & 06 & 08 & 10 & 23 & 25 & 31 \\
\hline \begin{tabular}{|l|}
$\mathrm{T} 1$ \\
\end{tabular} & 01 & 05 & 02 & 32 & 14 & 27 & 19 & 30 \\
\hline \begin{tabular}{|l|} 
T2 \\
\end{tabular} & 03 & 09 & 11 & 17 & 24 & 29 & 15 & 26 \\
\hline \begin{tabular}{|l|} 
T3 \\
\end{tabular} & 07 & 20 & 13 & 18 & 16 & 28 & 12 & 21 \\
\hline
\end{tabular}

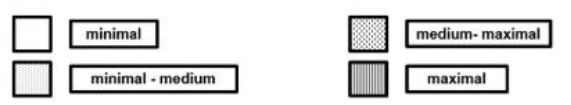

Figure 3: Arrangement of the four different sets of eight cartridges each prior to the different treatments. C: control; T1: $600 \mu \mathrm{g}^{*} \mathrm{l}^{-1}$ AgNPs; T2: $2.4 \mathrm{mg}^{\star} \mathrm{l}-1$ AgNPs; T3: $2.4 \mathrm{mg}^{*} \mathrm{l}^{-1} \mathrm{AgNO}_{3}$.
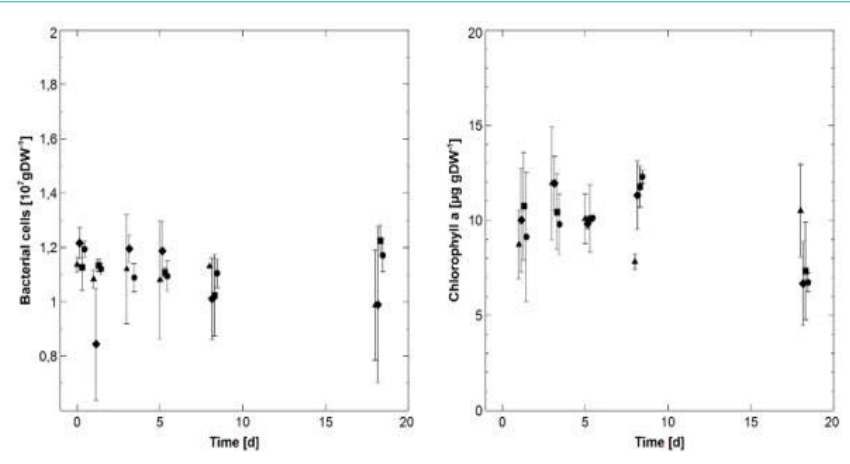

Figure 4: Temporal development of the microbial biomass of the biofilms (mean values with corresponding STDev): triangles: control (C); diamonds: $600 \mu g^{*} \mathrm{l}-1$ AgNPs (T1); squares: $2.4 \mathrm{mg}^{*} \mathrm{l}^{-1}$ AgNPs (T2); circles: $2.4 \mathrm{mg}^{*} \mathrm{l}^{-1}$ $\mathrm{AgNO}_{3}(\mathrm{~T} 3)$; left: Bacterial cell counts $(n=3)$; right: algal biomass determined via Chlorophyll $a(n=3)$.

$\mathrm{ml}$. Six of these single samples were pooled, thoroughly mixed with a sterile spatula and $0.5 \mathrm{ml}$ or $1 \mathrm{ml}$ each were transferred into new reaction tubes for further analyses and the Dry Weight (DW) of the samples was recorded.

\section{EPS and microbial biomass}

The colloidal fraction of the Extracellular Polymeric Substances (EPS) was extracted from the biofilm samples according to Gerbersdorfet al. [23]. Subsequently, the content of EPS carbohydrates was determined by phenol assays after Dubois et al. [24]. while the content of extracellular proteins was measured using a modified Lowry method $[25,26]$. Algal biomass, chlorophyll a/ pheophytin contents were analyzed according to the DIN $38412 / 16$ protocol by measured triplicates of ethanol extracts before and after acidification. The bacterial biomass was determined as follows: samples fixed with $4 \%$ paraformaldehyde (final concentration) were shaken horizontally for $1 \mathrm{~min}$ and treated ( 2 pulses for $3 \mathrm{~s}$ at $10 \%$ intensity) with a Sonopuls UW 3100 ultrasonic probe (Bandelin electronic, Berlin, Germany). After sedimentation of the sediment grains for $1 \mathrm{~min}$, subsamples of $198 \mu \mathrm{L}$ were taken from the supernatant and stained with $2 \mu \mathrm{L}$ SYTO $13(500 \mu \mathrm{M})$ (Life Technologies, Carlsbad, CA, USA) for $15 \mathrm{~min}$. Triplicates of the bacterial cell samples were counted at $488 \mathrm{~nm}$ excitation using a flow cytometer (FACScalibur, BD Bio Science, New Jersey, USA. Calibration was performed using a pure culture of Acidovoraxavenaestained as given above and calibration with an undyed biofilm subsample of $200 \mu \mathrm{l}$ of each sample.

\section{Microbial biostabilization}

Assessment of stabilization capacity of the biofilms was performed using a MagPI (Magnetic Particle Induction) system [27] that was modified according to Schmidt et al. [18], by spreading ferromagnetic particles (diameter 200-350 $\mu \mathrm{m}$; Partrac, UK) on the biofilm surface. These particles were subsequently attracted by an electromagnetic inductor that was set in a definite distance of $4 \mathrm{~mm}$ from the biofilm surface. Adhesion forces of the biofilm surface were regarded as equivalent to the amperage required to retrieve the particles. As the function defining the relation between the measured adhesion force and the overall erosion resistance of the biofilm covered sediment is still unknown, the term "biofilm adhesiveness" is used as a reliable proxy for the overall biofilm stability.

\section{Statistical analyses}

For statistical evaluation of the results, normal distribution of the data sets was checked with Shapiro-Wilks tests (confidence interval 95\%) using the software package Analyze-it225 (1.0.5.0.). In order to compare the different groups, a one-way ANOVA (confidence interval 95\%; chi -square approximation; Tukey error protection) was performed if data were normally distributed. Otherwise, a KruskalWallis test (KWT) (chi -square approximation; Bonferroni correction for ties) was conducted.

\section{Results and Discussion}

\section{Microbial biomass}

Overall, the total Bacterial Cell Counts (BCC) of the biofilms showed few fluctuations over time. The only exception could be found in biofilms of T1 which displayed a decrease in bacterial cells comparing the state before the treatment with AgNPs and the first sampling point, followed by an increase to the original level on the third day. Here, the mean BCC decreased from $1.22 \pm 0.06$ to 0.84 $\pm 0.21^{*} 10^{7}$ cells $\mathrm{g} \mathrm{DW}^{-1}$ and increased again to a mean value of 1.20 $\pm 0.05^{*} 10^{7}$ cells $\mathrm{g} \mathrm{DW}^{-1}$. During the same period - and until day 8 , the mean bacterial cell counts of the other biofilms remained stable at a level of approximately $1.12 \pm 0.2^{*} 10^{7}$ cells $\mathrm{g} \mathrm{DW}^{-1}$. On day 18 of the experiment, biofilms originated from $\mathrm{C}$ and $\mathrm{T} 1$ displayed slightly lower mean bacterial cell counts than those from T2 and T3 (Figure 4). However, at no point during the experiment, a significant difference in BCC could be detected between the different treatments and/ or the control.

In contrast to that, the temporal development of the algal biomass appeared to be more complex: in the control biofilms, mean chlorophyll a contents increased from the first to the third day reaching a maximal mean value of $11.94 \pm 2.97 \mu \mathrm{g}$ g DW -1 , followed by a decrease and a final increase to $10.50 \pm 2.44 \mu \mathrm{g} \mathrm{DW}^{-1}$ on day 18. The mean chlorophyll a contents of biofilms of T1 fluctuated until day 8 (with a maximum on day two with $11.94 \pm 1.44 \mu \mathrm{g} \mathrm{DW}^{-1}$ ) and finally dropped until day 18 to $6.67 \pm 2.21 \mu \mathrm{g}$ g DW -1 . Biofilms of T2 and $\mathrm{T} 3$ reached maximal mean chlorophyll a contents on day 8 (T2: $11,76 \pm 1.08 \mu \mathrm{g}$ g DW -1; T3: 12,29 $\pm 0.33 \mu \mathrm{g}$ g DW -1) followed by a decrease to a similar level as detected in T1. Although no significant differences in chlorophyll a contents could be found comparing the different treatments with the control, a strong trend was detected on day 8 as well as on day 18 (KWT: $\mathrm{p}=0.5210$ for day $8 ; \mathrm{p}=0,5045$ for day 18 ; for both $\mathrm{n}=3$ ). 

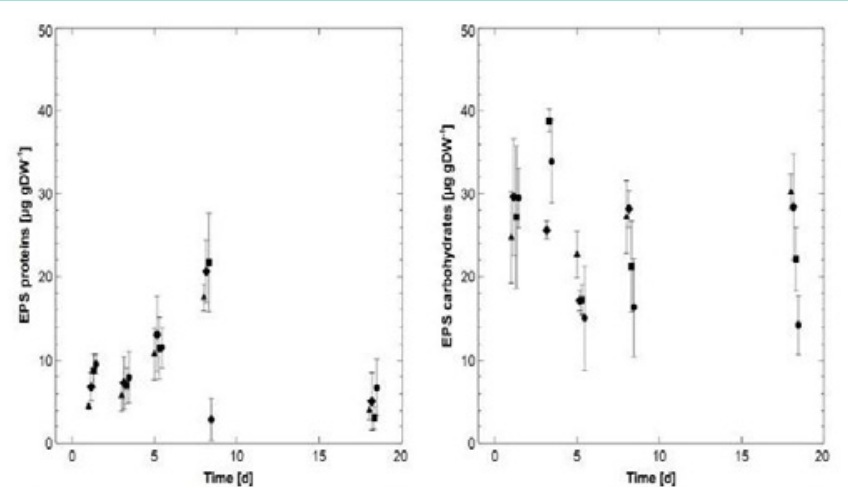

Figure 5: Temporal development of the colloidal EPS compounds of the biofilms (mean values with corresponding STDev): triangles: control (C); diamonds: $600 \mathrm{\mu g}^{*} \mathrm{l}^{-1}$ AgNPs (T1); squares: $2.4 \mathrm{mg}^{*} \mathrm{l}^{-1}$ AgNPs (T2); circles: 2.4 $\mathrm{mg}^{*} \mathrm{l}^{-1} \mathrm{AgNO}_{3}$ (T3); left: EPS protein contents $(n=3)$; right: EPS carbohydrate contents $(n=3)$.

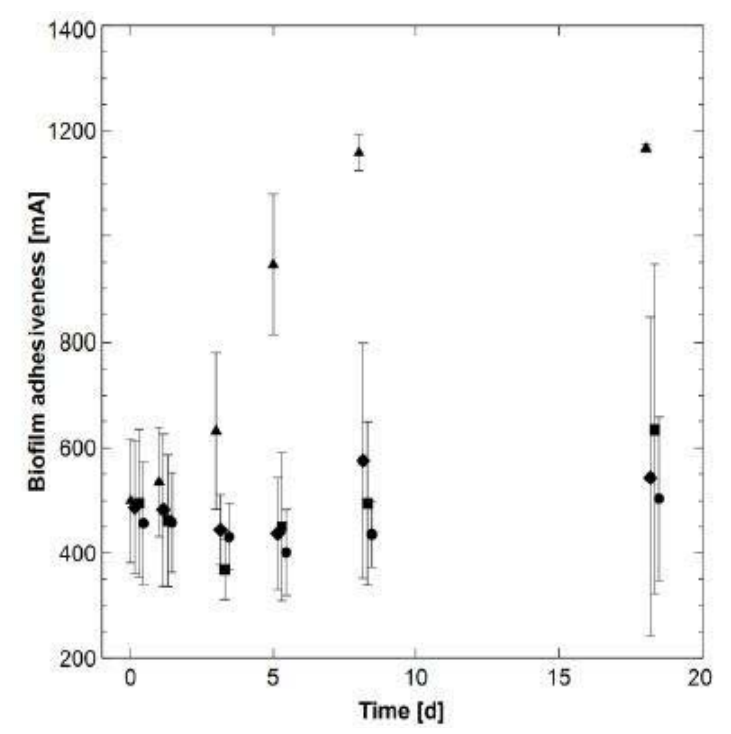

Figure 6: Temporal development of the biofilm adhesiveness (mean values with corresponding STDev): triangles: control (C); diamonds: $600 \mu^{*} \mathrm{l}^{-1}$ AgNPs (T1); squares: 2.4 mg $^{*} \mathrm{l}-1$ AgNPs (T2); circles: $2.4 \mathrm{mg}^{*} \mathrm{I}^{-1} \mathrm{AgNO}_{3}(\mathrm{~T} 3)$.

\section{EPS composition}

The analyzed EPS carbohydrates and EPS proteins displayed clear differences in their temporal development. The mean contents of the EPS carbohydrates fluctuated between day 1 and 5 with the highest mean value of $3.8 \pm 1.4 \mu \mathrm{g} \mathrm{g} \mathrm{DW}{ }^{-1}$ detected on day 3 in $\mathrm{T} 2$ and the lowest value of $15.0 \pm 6.2 \mathrm{~g} \mathrm{DW}^{-1}$ on day 5 in T3. From day 8 on, the mean values remained at a constant level. Notably, from day 5 on, T2 and $\mathrm{T} 3$ tended to display the lowest mean values while higher mean EPS carbohydrate contents were determined in C and T1. However, this difference in the long-term development (day 5 -18) between the different treatments/ control was not significant, although a trend was visible between $\mathrm{C}$ and T3 (KWT: $\mathrm{p}=0.56 ; \mathrm{n}=9$ ) (Figure 5). On day 1 , the mean EPS protein contents ranged from $4.5 \pm 0.4 \mathrm{~g}$ $\mathrm{DW}^{-1}$ (C) to $9.6 \pm 1.2 \mu \mathrm{g}$ g DW -1 (T3). Until day 8 , the mean protein contents significantly increased in C, T1 and T2 (KWT: p=0.1243; $\mathrm{n}=12$ ), while it decreased to a minimum of $2.9 \pm 2.5 \mu \mathrm{g} \mathrm{g} \mathrm{DW}^{-1}$ in T3 after approximately staying at the same level until day 5 . At the last sampling on day 18, all samples (C, T1, T2 and T3) displayed comparably low mean EPS protein contents ranging from $3.1 \pm 1.4$ $\mu \mathrm{g} \mathrm{DW}^{-1}$ in $\mathrm{T} 2$ to $6.7 \pm 3.4 \mu \mathrm{g} \mathrm{DW}^{-1}$ in T3. For C, T1 and T2, these mean values were significantly lower than the values measured on day 8 (KWT: $\mathrm{p}=0.1243 ; \mathrm{n}=9$ ).

\section{Biofilm adhesiveness}

At the first and second day of the experiment, the biofilms of the three different treatments (T1; T2; T3) displayed very similar levels of biofilm adhesiveness as the mean value in the control (C) of $465.7 \pm 104.8 \mathrm{~mA}$ (KWT: $\mathrm{p}=0.2901 ; \mathrm{n}=36$ ). However, while the adhesiveness of pristine biofilms significantly increased until day 8 (KWT: $\mathrm{p}<0.0001 ; \mathrm{n}=24$ ) and stayed at this high level until day 18 , the adhesiveness of biofilms treated with AgNPs orAgNO3 stagnated on a lower level (KWT: T1: $\mathrm{p}=0.3283$; T3: $\mathrm{p}=0.4691$; for both $\mathrm{n}=24$ ). Biofilm adhesiveness of $\mathrm{T} 2$ even displayed a clear decrease and a significant minimum of $368.4 \pm 56.9 \mathrm{~mA}$ on day 6 (KWT: $\mathrm{p}=0.0159$; $\mathrm{n}=24$ ) (Figure 6). Subsequently, biofilm stability increased until day 21 up to $634.5 \pm 311.6 \mathrm{~mA}$ which was comparable to the level of the other treatments. Thus, although all biofilms showed very comparable levels of initial adhesiveness, a significant difference between the control and the treatments could be detected (KWT: $<<0.0001 ; \mathrm{n}=96$ ).

\section{The impact of AgNPs on biofilms}

Although Xiu et al. [28], suggested a release of ionic silver which can damage the cell membranes as the main reason for the antimicrobial effect of AgNPs, the exact mode of operation of AgNPs is still unclear and recent studies indicated the high stability of AgNPs [21,22]. Besides the open question concerning the AgNP mediated effects, there is also a great lack of knowledge regarding the ecotoxicological impact of an exposure to AgNPs on complex multi-species and -taxa microbial test systems. In particular, the possible impairment of ecosystem services and functions associated with complex natural microbial assemblages is of high ecological and economic importance. In this context, several studies investigated the effect of an exposure to relatively high concentrations of AgNPs on activated sludge $[29,30]$ or soil involving nitrifying microbes [31]. These studies presented an ambivalent picture, indicating no direct lethal effect on matured biofilm communities, but shifts in the microbial community composition which were suggested to possibly cause a loss of biofilm functionality. Similar results were shown in our recent studies $[18,20]$ confirming no lethal effects on microbial viability after AgNP exposure, but significant impact on the overall structure and the stability of the complex biofilm network. The study presented here is the first attempt to address the effects of AgNPs on more complex, natural-like benthic biofilm communities under controlled natural-like boundary conditions. Thus, the ecological significance of this mescocosm study is comparable higher than the previous studies dealing with mono-species biofilm assays.

The comprehensive approach comprises the ecotoxicological effect assessment of silver nanoparticles on different biofilm compartments: the microbial biomass, the produced EPS and the biofilm adhesiveness as a proxy for the overall functionality of the biofilm system. Concerning the microbial biomass, no significant effect of silver exposure could be detected. No clear impact on bacterial cell counts was visible - although the used method determined total bacterial cells without differentiation between 
live and dead cells. However, recent experiments into the viability of mono-species biofilms after exposure to AgNPs support this assumption (Schmidt et al., unpublished). The results of this study indicate a putative long-term effect 18 days after AgNP exposure on the microalgae community independent from the silver species used. This might be caused by the higher metabolic turnover and longer life span of microalgae resulting in a higher accumulation potential compared to bacteria. A further reason for the lower susceptibility of biofilms to AgNPs compared to planktonic cells [32] is given by the EPS matrix that can constitute a protective barrier against exterior harmful impacts [33]. Choi et al. [34] reported a four times higher resistance of biofilms against AgNPs than planktonic bacteria of the same species which supports this assumption. Silvestry-Rodriguez et al. [35] could show that biofilms can take up great amounts of ionic silver without significant impact on the bacterial population. In our study, there was no statistically significant effect on the EPS protein content after the exposure to AgNP, and for the EPS carbohydrates only a weak reaction was indicated after exposure to $2.4 \mathrm{mg} / \mathrm{AgNO}_{3}$ and $2.4 \mathrm{mg} / \mathrm{l} \mathrm{AgNPs}$, respectively. These effects were less clear than the recent observations reported by Schmidt et al. [18] which is probably due to the multitude of functional redundancies in the natural-like biofilm system compared to a mono-species biofilm. In the past, different investigations could show that the production of EPS in biofilms can be increased in the presence of environmental stress $[19,36,37]$, but this was reported to be correlated with an decrease in the abundance of bacteria and microalgae.

\section{The role of the EPS matrix}

The EPS matrix is known as a major driving factor for the development of the diffusion limited biofilm system that also influences the transport of nanoparticles [38]. In this context, various parameters may influence the transport of nanoparticles within the EPS matrix including the density and porosity of the biofilm [39], the charge of the EPS matrix $[38,40]$ as well as the size, charge and shape of the nanoparticles [41,42]. As an example, Neal [40] reported the repulsion of negatively charged nanoparticles from a negatively charged EPS matrix. Peulen \& Wilkinson [38]. Showed that sizes of $50 \mathrm{~nm}$ and greater could limit the penetration of nanoparticles into the biofilm. As AgNPs of a size of 50nm were used in this study, a potential accumulation of nanoparticles at the biofilm surface may have hampered the further penetration into deeper biofilm layers. This assumption is supported by the enhanced agglomeration of silver nanoparticles in the presence of an EPS matrix reported by Choi et al. [34]. Due to the absorbance and subsequent agglomeration at the biofilm surface [43], followed by a limited diffusion of the AgNPs, deeper layers of the biofilm could be largely unaffected by the exposure to the nanoparticles. This also explains the described development of the microbial biomass displaying no significant decrease in the exposed samples, while the surface adhesiveness of the biofilms was significantly impacted.

\section{Biofilm adhesiveness as marker for biofilm functionality}

The adhesiveness of the biofilm constitutes a marker for the capability to stabilize the underlying fine sediment and was impacted independently from the silver species the biofilms were exposed to. This suggests a variety of downstream effects on different driving factors for the benthic system including the erosion resistance of the fine sediment, the characteristics of suspended flocs or the absorption of suspended particles. Furthermore, the associated ecosystem functions such as the nutrient cycling and the integrity of the benthic food web may be affected. It is important to note, that the microbial biostabilization of fine sediments is known as a highly complex process depending on a broad variety of environmental parameters [4]. In particular, the exact correlation of biofilm adhesiveness to the hydraulic parameters and driving factors is not fully understood yet. As an example, Yallopet al. [1] reported a strong correlation of the microbial biostabilization to the algal biomass and the content of EPS carbohydrates in highly productive mudflat biofilms. However, in riverine biofilms, EPS proteins were suggested to play an even more decisive role than the EPS carbohydrates [16]. Furthermore, the complex interactions between the bacteria and microalgae defined the structure and adhesiveness of the biofilm matrix [44] which in turn influenced the stabilizing capacity of the biofilms. Moreover, functional key players within the community of bacteria and microalgae are relevant factors for the adhesiveness of the biofilm [16]. The numerical abundance of these taxa shifts depending to the different environmental conditions (Schmidt et al. accepted). The complexity of the microbial biostabilization emphasizes one of the main advantages of the MagPI system: it facilitates direct in situ measurements of the overall surface adhesiveness as a resulting sum parameter of various interplays. The reliability of this proxy for the biofilm stability - especially in young biofilms - could be demonstrated in previous experiments [14]. There is still ongoing research revealing the exact correlation between biofilm adhesiveness and biofilm stability. However, the high sensitivity and both temporal and spatial resolution power of the MagPI system offers a useful tool to assess the functionality of different benthic habitats under the impact of various anthropogenic stressors.

\section{Conclusion}

The aim of this study was to assess the damage potential of AgNPs for benthic ecosystems and associated ecosystem functions. In contrast to previous investigations, natural complex biofilms were cultivated in a sediment mesocosm setup under natural-like conditions. Analyses could demonstrate that parameters established in the analytic routine (microbial biomass and EPS) are unable to describe the full impact of AgNPs on biofilm functionality. Bacteria as well as microalgae did not display a significant decrease in viability after the exposure to AgNPs. One reason for this observation may be found in the protective function of the EPS layer covering the microbes in the biofilm causing agglomeration and limited diffusion of the AgNPs. However, clear effects on biofilm adhesiveness after the exposure to AgNPs as well as $\mathrm{AgNO}_{3}$ could be detected. This suggests the enrichment and main impact of silver at the surface of the biofilm. Moreover, no clear relationship between EPS quantity - which is commonly supposed to be a driving factor during the process of microbial biostabilization - and biofilm adhesiveness could be found. This observation emphasizes the high complexity of this ecosystem function and the need of further research. In this context, the MagPI system constitutes a straight forward tool for future analytic approaches to address the ecosystem services associated with the stability of the biofilm/ fine sediment habitat.

\section{Acknowledgement}

This study was kindly supported by the German Research 
Foundation (DFG; Research unit INTERNANO: FOR 1536, subprojects BIOFILM MA3273/3-2 and MASK SCHA849/16-2).

\section{References}

1. Yallop ML, Paterson DM, Wellsbury P. Interrelationships between rates of microbial production, exopolymer production, microbial biomass, and sediment stability in biofilms of intertidal sediments. Microbial Ecology. 2000; 39: 116-127.

2. Gerbersdorf SU, Jancke T, Westrich B. Sediment properties for assessing the erosion risk of contaminated riverine sites. Journal of Soils and Sediments. 2007; 7: 25-35.

3. Gerbersdorf SU, Hollert H, Brinkmann M, Wieprecht S, Schuettrumpf $H$ Manz W, et al. Anthropogenic pollutants affect ecosystem services of freshwater sediments: the need for a "triad plus x" approach. Journal of Soils and Sediments. 2011; 11: 1099-1114.

4. Gerbersdorf SU, Wieprecht S. Biostabilization of cohesive sediments: revisiting the role of abiotic conditions, physiology and diversity of microbes, polymeric secretion, and biofilm architecture. Geobiology. 2015; 13: 68-97.

5. Timoner X, Buchaca T, Acuna V, Sabater S. Photosynthetic pigment changes and adaptations in biofilms in response to flow intermittency. Aquat Sci. 2014; 76: $565-578$

6. Barthes A, Ten-Hage L, Lamy A, Rols JL, Leflaive J. Resilience of Aggregated Microbial Communities Subjected to Drought-Small-Scale Studies. Microbial Ecology. 2015; 70: 9-20.

7. Winkworth $\mathrm{CL}$, Lear G. Antimicrobial potential of the ionophore monensin on freshwater biofilm bacteria. Environmental Science and Pollution Research. 2014; $21:$ 10139-1150.

8. Lawrence JR, Topp E, Waiser MJ, Tumber V, Roy J, Swerhone GDW, et al. Resilience and recovery: The effect of triclosan exposure timing during development, on the structure and function of river biofilm communities. Aquatic Toxicology. 2015; 161: 253-266.

9. Kamjumphol W, Chareonsudjai P, Taweechaisupapong S, Chareonsudjai S Morphological Alteration and Survival of Burkholderia pseudomallei in Soil Microcosms. Am J Trop Med Hyg. 2015; 93: 1058-1065.

10. Sachidanandham R, Gin KYH. A dormancy state in nonspore-forming bacteria. Appl Microbiol Biotechnol. 2009; 81: 927-941.

11. Gomez-Alvarez V, Pfaller S, Pressman JG, Wahman DG, Revetta RP Resilience of microbial communities in a simulated drinking water distribution system subjected to disturbances: role of conditionally rare taxa and potential implications for antibiotic-resistant bacteria. Environ Sci-Wat Res Technol. 2016; 2: 645-657.

12. Weaver L, Webber JB, Hickson AC, Abraham PM, Close ME. Biofilm resilience to desiccation in groundwater aquifers: A laboratory and field study. Science of the Total Environment. 2015; 514: 281-289.

13. Flemming HC, Wingender J, Griebe T, Mayer C. Physio-Chemcal Properties of Biofilms. In: Evans LV, editor. Biofilms: Recent Advances in their Study and Control: CRC Press; 2000.

14. Thom M, Schmidt H, Wieprecht S, Gerbersdorf S. Biostabilization of fluvia sediments: An improved device to address an old problem. IAHR; Den Haag, Netherlands. 2015

15. Thom M, Schmidt H, Gerbersdorf SU, Wieprecht S. Seasonal biostabilization and erosion behavior of fluvial biofilms under different hydrodynamic and ligh conditions. International Journal of Sediment Research. 2015; 30: 273-284.

16. Schmidt H, Thom M, King L, Wieprecht S, Gerbersdorf SU. The effect of seasonality upon the development of lotic biofilms and microbial biostabilisation. Freshwater Biology. 2016.

17. Grün A, Meier J, Metrevelli G, Schaumann G, Manz W. Sublethal concentrations of silver nanoparticles affect the mechanical stability of biofilms. Environmental Science and Pollution Research. 2016; 23: 24277 24288

18. Schmidt H, Thom M, Madzgalla M, Gerbersdorf SU, Metreveli G, Manz W.
Exposure to silver nanoparticles affects biofilm structure and adhesiveness. Aquatic Pollution and Toxology. 2017; 1 : 2.

19. Lubarsky HV, Gerbersdorf SU, Hubas C, Behrens S, Ricciardi F, Paterson DM, et al. Impairment of the Bacterial Biofilm Stability by Triclosan. Plos One. 2012; 7 .

20. Grun AY, Meier J, Metreveli G, Schaumann GE, Manz W. Sublethal concentrations of silver nanoparticles affect the mechanical stability of biofilms. Environmental Science and Pollution Research. 2016; 23: 2427724288.

21. Metreveli G, Philippe A, Schaumann GE. Disaggregation of silver nanoparticle homoaggregates in a river water matrix. Science of the Total Environment. 2015; 535: 35-44

22. Metreveli G, Frombold B, Seitz F, Grun A, Philippe A, Rosenfeldt RR, et al. Impact of chemical composition of ecotoxicological test media on the stability and aggregation status of silver nanoparticles. Environ-Sci Nano. 2016; 3: 418-433.

23. Gerbersdorf SU, Jancke T, Westrich B, Paterson DM. Microbial stabilization of riverine sediments by extracellular polymeric substances. Geobiology. 2008; 6: 57-69.

24. Dubois M, Gilles KA, Hamilton JK, Rebers PA, Smith F. Colorimetric method for determination of sugars and related substances. Analytical Chemistry. 1956; 28: 350-356.

25. Raunkjaer K, Hvitvedjacobsen T, Nielsen PH. Measurement of pools of protein, carbohydrate and lipid in domestic wastewater. Water Research. 1994; 28: 251-262.

26. Frolund B, Palmgren R, Keiding K, Nielsen PH. Extraction of extracellular polymers from activated sludge using a cation exchange resin. Water Research. 1996; 30: 1749-1758.

27. Larson F, Lubarsky H, Gerbersdorf SU, Paterson DM. Surface adhesion measurements in aquatic biofilms using magnetic particle induction: MagPI. Limnology and Oceanography-Methods. 2009; 7: 490-497.

28. Xiu Z-m, Zhang Q-b, Puppala HL, Colvin VL, Alvarez PJJ. Negligible ParticleSpecific Antibacterial Activity of Silver Nanoparticles. Nano Letters. 2012; 12: $4271-4275$

29. Sun X, Sheng Z, Liu Y. Effects of silver nanoparticles on microbial community structure in activated sludge. Science of the Total Environment. 2013; 443: 828-835.

30. Shang ZY, Van Nostrand JD, Zhou JZ, Liu Y. The effects of silver nanoparticles on intact wastewater biofilms. Frontiers in Microbiology. 2015; 6: 11.

31. Wang JA, Shu KH, Zhang L, Si YB. Effects of Silver Nanoparticles on Soil Microbial Communities and Bacterial Nitrification in Suburban Vegetable Soils. Pedosphere. 2017; 27: 482-490.

32. Navarro E, Piccapietra F, Wagner B, Marconi F, Kaegi R, Odzak N, et al. Toxicity of Silver Nanoparticles to Chlamydomonas reinhardtii. Environmental Science \& Technology. 2008; 42: 8959-8964

33. Wingender J, Neu T, Flemming $\mathrm{H}$. What are Bacterial Extracellular Polymeric Substances. In: Wingender $\mathrm{J}$, Neu T, Flemming $\mathrm{H}$, editors. Microbial Extracellular Polymeric Substances. Heidelberg: Springer Berlin; 1999.

34. Choi O, Yu C-P, Fernandez GE, Hu Z. Interactions of nanosilver with Escherichia coli cells in planktonic and biofilm cultures. Water Research. 2010; 44: 6095-6103.

35. Silvestry-Rodriguez N, Bright KR, Slack DC, Uhlmann DR, Gerba CP. Silver as a residual disinfectant to prevent biofilm formation in water distribution systems. Applied and Environmental Microbiology. 2008; 74: 1639-1641.

36. Mason CF, Underwood GJC, Baker NR, Davey PA, Davidson I, Hanlon G, et al. The role of herbicides in the erosion of salt marshes in eastern England. Environmental Pollution. 2003; 122: 41-49.

37. Garcia-Meza JV, Barrangue C, Admiraal W. Biofilm formation by algae as a mechanism for surviving on mine tailings. Environmental Toxicology and Chemistry. 2005; 24: 573-581. 
38. Peulen TO, Wilkinson KJ. Diffusion of Nanoparticles in a Biofilm Environmental Science \& Technology. 2011; 45: 3367-3373.

39. Sahle-Demessie E, Tadesse H. Kinetics and equilibrium adsorption of nanoTiO2 particles on synthetic biofilm. Surf Sci. 2011; 605: 1177-1184.

40. Neal AL. What can be inferred from bacterium-nanoparticle interactions about the potential consequences of environmental exposure to nanoparticles? Ecotoxicology. 2008; 17: 362-371

41. Pal S, Tak YK, Song JM. Does the antibacterial activity of silver nanoparticles depend on the shape of the nanoparticle? A study of the gram-negative bacterium Escherichia coli. Applied and Environmental Microbiology. 2007; 73: $1712-1720$
42. Choi O, Hu ZQ. Size dependent and reactive oxygen species related nanosilver toxicity to nitrifying bacteria. Environmental Science \& Technology. 2008; 42: 4583-4588.

43. Ikuma K, Decho AW, Lau BLT. When nanoparticles meet biofilms-interactions guiding the environmental fate and accumulation of nanoparticles. Frontiers in Microbiology. 2015; 6: 6.

44. Schmidt H, Thom M, Matthies K, Behrens S, Obst U, Wieprecht S, et al. A multi-disciplinarily designed mesocosm to address the complex flowsediment-ecology tripartite relationship on the microscale. Environmental Science Europe. 2015; 27: 1-11.
Austin J Environ Toxicol - Volume 4 Issue 1 - 2018

ISSN: 2472-372X | www.austinpublishinggroup.com

Schmidt et al. (C) All rights are reserved
Citation: Schmidt H, Gerbersdorf SU, Ullrich X, Thom M and Manz W. Biofilm Adhesiveness is a Reliable Proxy for the Effect Assessment of Silver Nanoparticles on the Functionality of Freshwater Biofilms. Austin J Environ Toxicol. 2018; 4(1): 1022. 